\title{
Cross-Disciplinary Collaboration and Scholarly Independence in Multidisciplinary Learning Environments at Doctoral Level and Beyond
}

\author{
Eva M. Brodin ${ }^{1,2}$ (D) Helen Avery $^{3}$
}

Published online: 22 February 2020

(C) The Author(s) 2020

\begin{abstract}
The aim of this study is to investigate how patterns of collaboration and scholarly independence are related to early stage researchers' development in two multidisciplinary learning environments at a Swedish university. Based on interviews with leaders, supervisors, doctoral students, and post docs, results show how early stage researchers' development is conditioned by their relative positions in time (career stage) and space (geographical and epistemic position). Through the theoretical notions of 'epistemic living space' and 'developmental networks', four ways of experiencing the multidisciplinary learning environment were distinguished. Overall, the environments provided a world of opportunities, where the epistemic living space entailed many possibilities for cross-disciplinary collaboration and development of scholarly independence among peers. However, depending on the members' relative positions in time and space, this world became an alien world for the post docs who had been forced to become "over-independent" and find collaborators elsewhere. Moreover, it became an avoided world for absent mono-disciplinary supervisors and students who embodied "non-collective independence", away from the environments' community. By contrast, a joint world emerged for doctoral students located in the environment, which promoted their "independent positioning" and collaborative ambitions. Thus, early stage researchers' collaboration and development of scholarly independence were optimised in a converged learning space, where the temporal and spatial conditions were integrated and equally conducive for
\end{abstract}

Eva M. Brodin

eva.brodin@ahu.lu.se

Helen Avery

helen.avery@cme.lu.se

1 Department of Educational Sciences, Lund University, Lund, Sweden

2 Centre for Higher and Adult Education, Stellenbosch University, Stellenbosch, South Africa

3 Centre for Middle Eastern Studies, Lund University, Lund, Sweden 
learning. Based on these results, the authors provide suggestions for how to improve the integration of scholars who tend to develop away from the community because of their temporal and spatial positions.

Keywords Doctoral students $\cdot$ Post docs $\cdot$ Collaboration $\cdot$ Scholarly independence $\cdot$ Interdisciplinary $\cdot$ Transdisciplinary

\section{Introduction}

Before the 1990s, research across disciplinary boundaries was primarily initiated by academic interests, while it has now become a political concern for addressing global challenges (Kessel and Rosenfield 2008; UNESCO 2019). Nevertheless, numerous studies show that cross-disciplinary research is no easy road, since university structures, funding and publication avenues tend to be organised along disciplinary lines (Albert et al. 2009; Lewis et al. 2016; Turner et al. 2015). Doctoral students in such settings face additional problems in having to form their scholarly identity without clear guiding principles (Boden et al. 2011; Felt et al. 2013). Even though these concerns were raised already in the 1960s (Blöschl et al. 2012), pedagogical research in this field is still very scarce. Moreover, focused studies on post docs' learning in multidisciplinary environments are lacking, despite evidence suggesting that post docs also need support from scientific supervisors and career mentors for their development (Scaffidi and Berman 2011).

Against this background, we will in this study examine the learning conditions of doctoral students and post docs in two multidisciplinary research environments placed at the same Swedish research university. A new conceptual framework will be proposed to better understand how structures and activities in the doctoral schools affect early stage researchers' opportunities to collaborate and develop scholarly independence. In an earlier analysis of the doctoral students' conditions for developing creativity in these environments, we found that the silence around varying epistemic values was a barrier to their development (Brodin and Avery 2014). The current study draws on interviews with both early stage and senior researchers to analyse how patterns of collaboration and scholarly independence are related to the early stage researchers' relative positions in time and space with respect to stage in their career paths, institutional position and physical location.

\section{Forms of Disciplinarity}

Although it has been stressed, from an anthropological perspective, that disciplines are incongruent with the flowing boundaries of contemporary academia in many respects (Brew 2008), disciplinary modes of being still have an impact on scholars in practice. Disciplines can be understood as "intellectual structures in which the transfer of knowledge from one generation to the next is cast; that is, they shape the entire system of education" (Weingart and Stehr 2000: xi). In line with this definition, we will use the single term of "discipline" to signify mono-disciplines, while 
"cross-disciplinary core discipline" will refer to the studied environments' broader disciplines, characterised by a cross-disciplinary approach, in which multiple disciplines are integrated.

When several disciplinary traditions are at play in the same learning or research environment, the activities may be categorised as multidisciplinary, interdisciplinary, transdisciplinary, or cross-disciplinary. However, the terms are often used in exchangeable ways in practice (Townsend et al. 2015), and there is no consensus in the literature with respect to how the terms should be defined. There is considerable variation both concerning the types of environment where such research is undertaken, and as to the purpose of involving different disciplines. We will thus keep the terminology used by the authors we refer to, while remaining aware of the disparate definitions that might underlie these studies. Our own use of the concepts will be informed by the following definitions:

- Multidisciplinarity is understood as interaction between members from varying disciplines in academia, where the disciplinary boundaries are kept intact (Rosenfield 1992). Such collaboration could, for instance, involve a dialogue between critical friends from varying disciplines (Lewis et al. 2012).

- Interdisciplinarity is understood as some degree of integration between disciplines, such as when researchers approach a common problem from diverging disciplinary viewpoints (cf. Rosenfield 1992). With reference to Jakobsen et al. (2004), we suggest that interdisciplinary collaboration is unidirectional when the interaction is dominated by a single discipline, and goal-oriented when the interaction is driven by the identified issue rather than disciplinary hierarchies.

- Transdisciplinarity is understood as the most integrated form of knowledge making, where existing paradigms and research practices are dissolved and transformed into new theoretical and methodological approaches that do not appear in the parent disciplines (Fuqua 2012; Jakobsen et al. 2004; Rosenfield 1992).

- Cross-disciplinarity is used as an umbrella term for interdisciplinary and transdisciplinary research (Jakobsen et al. 2004), since interdisciplinary activities can become transdisciplinary over time. Although cross-disciplinary research is usually found in collaborative projects, it may also be performed by individual researchers who integrate knowledge and skills from more than one intellectual school or methodology (Brew 2008; Calvert 2010).

Furthermore, we will here label environments that involve more than one discipline 'multidisciplinary'. Although research environments can provide settings that are favourable to cross-disciplinary research, we argue that outcomes depend on the actions of the involved individuals and will take varying forms.

\section{Conceptual Framework}

Multidisciplinary environments provide their members a learning space with various affordances that allow them to develop skills, networks and scholarly independence. These affordances can enable varying degrees of disciplinary integration or 
transformation - the epistemic space - but can also be considered with respect to the dynamics at play in the social space. From this perspective, the locations and disciplinary profiles of the multidisciplinary environments in our study serve as indicators for the epistemic living space (cf. Felt et al. 2013) within which early stage researchers may develop through developmental networks (Baker and Lattuca 2010). We will now take a closer look at these central dimensions in the multidisciplinary learning space.

\section{The Epistemic Space}

Scholars in multidisciplinary contexts are constantly confronted with varying epistemic cultures concerning theories, instruments, collaboration styles, and ways of attaining social legitimacy (Knorr Cetina 1999). Whereas disciplinary incongruence in one or two of these aspects seldom ends in significant epistemic conflicts, disciplinary diversity in all dimensions most likely does (Heidler 2017). When the funders are historically allied with particular disciplinary directions (Albert et al. 2009; Jakobsen et al. 2004; Kessel and Rosenfield 2008), or when the interdisciplinary field of research is physically located at the departments of one parent discipline only (Wright and Ville 2017), it is common for one parent discipline to take the upper hand. In such contexts, the members from the dominating discipline not only tend to be superior in number, but they also set the norms and values for what counts as appropriate science, thereby hampering transdisciplinary development (Albert et al. 2009; Lewis et al. 2016; Wright and Ville 2017).

Competition for funding may also bring epistemic values to a head. Albert et al. (2009) found that even medical scientists with a positive attitude to social science were reluctant to invest more "medical" money in relevant social research, as they already struggled to fund their own research. Thus, even though cross-disciplinary collaboration ultimately aims to "leave your discipline at the door" (Boden et al. 2014), competitive structures will tend to force disciplinary communities to defend their own interests as a matter of survival.

\section{The Social Space}

Established cross-disciplinary centres are often led by their founders who are recognised not only for their scientific record, but also for their political skills, openmindedness and ability to "sell the programme" to potential scholars and varying stakeholders (Frost et al. 2004; Martimianakis and Muzzin 2015). But who are these potential scholars? Drawing on studies in the sociology of science, Braun (2012) predicts that the likelihood of scientists' migration from their existing domains into a new intellectual field of research is high if the new scientific field "generates expectations of higher reputation gain than in the case of a stay in the existing field; increases the expectations concerning resources, above all employment conditions; seems to have more promising answers to research questions" (p. 479). Braun (2012) points out that scientific migration also involves cognitive and social costs for the 
individual scholar, who needs to invest time in closing the cognitive gap between the existing and new field, and to develop new networks.

Not all cross-disciplinary researchers make a complete leap and double identities are usual, e.g. when the scholar works at a mono-disciplinary department while being affiliated to a multidisciplinary research centre. In this situation, empirical studies reveal that senior scholars tend to prioritise their mono-disciplinary department, while junior researchers are more open to adopting a transdisciplinary identity (Calvert 2010; Gardner et al. 2014; Martimianakis and Muzzin 2015). Yet Delamont et al. (2000) found that doctoral students in multidisciplinary departments may also hesitate to identify themselves as cross-disciplinary researchers when they have a mono-disciplinary background. For the purpose of our study, it is thus justified to ask how the social space needs to be shaped to encourage cross-disciplinary collaboration.

Research shows that cross-disciplinary engagement is significantly facilitated if the scholars work in the same building, since they can then strengthen their ties on a daily basis in informal communication (Jakobsen et al. 2004; Newswander and Borrego 2009). Initial discussions about the meaning of common concepts may also help communication across disciplines (Jakobsen et al. 2004). This facilitates the creation of a common ground (Öberg 2009), defined by Olson and Olson (2000) as "that knowledge that the participants have in common, and that they are aware that they have it in common" (p. 157). When there is a disciplinary distance between the collaborators from the outset, the creation of a common ground fundamentally relies on transparent and inclusive communication. This implies that epistemic cultures, concepts and values must be explicit (cf. Brodin and Avery 2014), as well as the individuals' expectations of the collaborative processes and potential outcomes (Boden et al. 2014; Bossio et al. 2014). In other words, the epistemic space is not static, but will evolve depending on the social and communicative dynamics of the environment, since both disciplinary values and positions are set in motion through social interaction.

\section{The Learning Space}

Empirical studies on doctoral students' socialisation in multidisciplinary environments show that peers are an important resource for learning (Boden et al. 2011; Gardner et al. 2014; Miller et al. 2016; Newswander and Borrego 2009; Ryan et al. 2012). Peers are also important resources for developing collaborative skills and scholarly independence, in the sense of the ability to critically position oneself in a field, while pragmatically moving one's research forward in new directions (Brodin 2016). In multidisciplinary learning environments, peers can contribute to shaping epistemic and social spaces where such positioning and pragmatic decisions may be tried out and offer the potential for collaborative projects, as the individuals' scholarly orientations become explicit.

Despite the importance of developing cross-disciplinary collaborative skills in interdisciplinary learning environments (Borrego and Newswander 2010), these skills are not always emphasised in the curricula of such doctoral programmes 
(Holley 2015). It is also difficult to find studies on how early stage researchers' cross-disciplinary collaboration works in practice, but the experimental case study of Hackett and Rhoten (2009) is an informative exception. They found that interdisciplinary doctoral students in their first and second study years performed better in collaboratively producing an interdisciplinary research proposal than students in their third and fourth year. By contrast, mono-disciplinary doctoral students showed a reversed pattern, where the more experienced students performed better in collaboratively creating an interdisciplinary research proposal. Such findings suggest that stage in time at which the doctoral students find themselves plays a significant role. In another study, Delamont et al. (2000) found that interdisciplinary collaboration among doctoral students seemed to be most successful within strong sub-disciplinary areas where the individuals shared the same interests.

Felt et al. (2013) have studied the 'epistemic living space' of transdisciplinary doctoral students in their final year, and we will in this study develop their work further by including the temporal and spatial dimensions of the epistemic living space(s) in doctoral students' and post docs' cross-disciplinary development. Conceptually, the epistemic living space captures the "intertwinedness of the personal, the institutional, the epistemic, the symbolic and the political" dimensions of living in research, where it is a matter of "feeling intellectually and socially 'at home', holding an understanding of the often non-codified sets of values which matter, feeling subjected to, being part of and performing certain temporal regimes, tacitly sharing a repertoire of practice to address knowledge questions, adapting to specific often complex funding arrangements and many more" (Felt 2009: 19, in Felt et al. 2013). Underpinned by the theoretical framework of Baker and Lattuca (2010), we further assume that the individuals' 'developmental networks' are central in this process, where "variations in a student's social interactions and relationships will be associated with variations in what is learned, valued and accepted" (p. 815).

\section{Scoping the Study}

In principle, two trajectories can be imagined in a given multidisciplinary learning space as defined above: developing scholarly independence away from the epistemic and social community; or developing independence through and toward the community in which the individuals find their unique and recognised scholarly position. In both cases, we hypothesise that the quality of the social interactions decides the outcome along with the individuals' relative positions in time and space. Time refers here to career stage, while space may be both geographic and epistemic (e.g. relating to a department which is physically located outside the multidisciplinary environment).

\section{Purpose}

The study investigates how patterns of collaboration and scholarly independence are related to early stage researchers' development in two multidisciplinary learning 
environments. Through the voices of the environments' leaders, supervisors, doctoral students and post docs, the following research questions are used to guide the inquiry:

- How do the individuals collaborate across the disciplines and who is involved?

- How is their engagement in the environments related to scholarly independence?

- In what ways do relative positions in time and space condition these processes?

\section{Method}

\section{Methodological Design}

This multi-case study of two multidisciplinary learning environments adopts an explanatory embedded case design (Yin 2014), which is suitable for explaining how and why certain phenomena develop in different directions. The embedded units of analysis used are "cross-disciplinary collaboration" and "scholarly independence", while explanations for observed patterns are found in characteristics of the environments, including the individuals' relative positions in time and space.

\section{Contexts and Participants}

The studied contexts consist of two equally large multidisciplinary learning environments (A and B) including their heads, directors of doctoral studies, doctoral students, supervisors, and post docs. The environments were selected to present similarities in the challenges of cross-disciplinary work, as well as differences with respect to organisation and objectives. Both environments are placed at a large Swedish research university, and each involves several disciplines across different faculties, ranging from the humanities and social sciences (HSS) to the STEM disciplines. The leaders of the environments had previously engaged in cross-disciplinary research and were strongly motivated to create conditions that would enable innovative cross-disciplinary research relating to their respective areas of concern. Both environments received large external long-term grants covering approximately the same period, allowing them to engage several post docs, doctoral students, and supervisors from varying departments. The environments were each organised around a cross-disciplinary core discipline, and attempted to widen the potential for the field by involving researchers and students from other disciplines. Apart from these similarities, the two environments differed in several respects at the time when data were collected, about three years after the establishment of their doctoral schools.

\section{Environment A}

Three faculties were involved in environment A (two from the STEM sciences and one from HSS), but the environment as a whole was dominated by researchers from 
Table 1 Participants from environment A

\begin{tabular}{llll}
\hline Role & Faculty X (STEM) & Faculty Y (STEM) & Faculty Z (HSS) \\
\hline Head of Environment & 1 (AHE) & & \\
Director of Doctoral studies & 1 (ADD) & & \\
Doctoral students & 2 (Ad1, Ad2) & 1 (Ad3) & \\
Supervisors & 2 (As1, As3) & 1 (As2) & 1 (Ap3) \\
Post docs & 2 (Ap1, Ap2) & & \\
\hline
\end{tabular}

varying disciplines within one of the STEM faculties. While most researchers in this environment were Swedish, some were international, notably the co-supervisors who were located at universities abroad. The members of the environment did not all work in the same university building, since their workplaces depended on disciplinary affiliations.

The doctoral students and the post docs had been admitted to the environment in connection to large ongoing projects in varying disciplines, and the post docs also ran their own projects. The doctoral students graduated in their own "home-discipline" while receiving multidisciplinary input from the environment. For instance, they had co-supervisors with varying scholarly backgrounds, and disciplinarily blended seminars were regularly organised, where the researchers could present their work in progress to all members connected to the environment. Two of the post docs interviewed for the study had a mono-disciplinary $\mathrm{PhD}$ (Ap1 and Ap2). The third post doc (Ap3) had an interdisciplinary $\mathrm{PhD}$ with an orientation toward HSS, where the profile was in line with the environment's overall research field.

Against this background, the epistemic orientation of environment A was characterised by unidirectional interdisciplinary features (cf. Jakobsen et al. 2004), although the leaders had the ambition to strengthen goal-oriented interdisciplinary collaboration across the involved faculties. In this regard, the post docs had a key position through their extended cross-disciplinary networks beyond the environment itself. A total of 11 researchers were included in the study from environment A, as outlined in Table 1.

\section{Environment B}

Four faculties were involved in environment B, one from STEM and three from HSS. Most of the researchers came from the HSS faculties with a fairly equal distribution between them. About half of the junior researchers and supervisors were international, and English was the everyday language in the environment. Almost all researchers and most of the doctoral students had their workplaces in the building of the research environment, while some supervisors and doctoral students had chosen to stay in their own disciplinary departments.

Both the doctoral students and the post docs had formulated their own projects as a part of the admission process. Furthermore, the doctoral students could choose to attain a PhD degree in their own "home-discipline", or in the cross-disciplinary 
Table 2 Participants from environment B

\begin{tabular}{lllll}
\hline Role & Faculty I (STEM) & Faculty II (HSS) & Faculty III (HSS) & Faculty IV (HSS) \\
\hline $\begin{array}{l}\text { Head of Environment } \\
\begin{array}{l}\text { Director of Doctoral } \\
\text { studies }\end{array}\end{array}$ & $1(\mathrm{BHE})$ & & & \\
Doctoral students & & & $1(\mathrm{BDD})$ & \\
Supervisors & $2(\mathrm{Bs} 2, \mathrm{Bs} 3)$ & $1(\mathrm{Bs} 1)$ & $1(\mathrm{Bs} 4)$ & \\
Post docs & & $1(\mathrm{Bp} 1)$ & $2(\mathrm{Bp} 2, \mathrm{Bp} 3)$ & \\
\hline
\end{tabular}

core discipline of the environment. About half had selected the latter alternative, and three of these students (Bd3-5) were included in this study, while the other two students (Bd1-2) planned to graduate in their "home-discipline". Like environment A, the doctoral students had supervisors with varying scholarly backgrounds, and disciplinarily blended seminars were arranged regularly in the environment. All three post docs had mono-disciplinary PhDs from the HSS. Several of the doctoral students and post docs had prior qualifications from programmes with cross-disciplinary approaches or had completed a master in a discipline other than their first area of studies.

Environment $B$ was thus more consistently organised to support cross-disciplinary collaboration and there were also ambitions of transdisciplinary research in the doctoral students' and post docs' individual work. A total of 14 participants were included in the study from environment B with varying disciplinary backgrounds as outlined in Table 2. All these participants were placed in the same building.

\section{Data Collection}

Data were collected through semi-structured interviews with a total of 25 participants (11 participants in environment A and 14 participants in environment B). While the leaders and some supervisors had extensive experience of cross-disciplinary collaboration (often with each other) before the doctoral schools were established, several doctoral students and supervisors, and some post docs, had no such prior experiences. At the time of the interviews, a few participants had about one year's experience of their multidisciplinary learning environment, while most had been involved for at least 2-3 years.

All participants were individually interviewed twice in Swedish or English depending on the participant's preferences, and each interview lasted for about 30-60 minutes. The interviews were based on open-ended questions that were asked in the same order and followed by spontaneous follow-up questions. The interviews covered the cross-disciplinary ambitions of the environment and its research, experienced boundaries (organisational and/or disciplinary), the scope for critical and creative thinking, the junior researchers' development of independence, and crossdisciplinary collaboration among the members of the environment. In the present study, analytical focus has been placed on issues of independence and collaboration, while answers to the other questions contributed with contextual understanding. All 
interviews were transcribed verbatim before analysis, and Swedish interview quotations have been translated into English in the results.

Besides the interviews, the authors of this study also observed a set of seminars in each environment to form their own impressions of the cross-disciplinary communication among the members. These direct observations functioned as an interpretative background for analysing the interviews, rather than as data for analysis in themselves (Yin 2014).

\section{Analysis}

Cross-case synthesis was used for analysing data since it is suitable for finding similar and diverging patterns in two or more cases (Yin 2014). In line with Yin's (2014) recommendations, each case was initially treated separately in the analysis before making comparisons, and the following procedure was applied:

1) All interview quotes relating to collaboration and independence were sorted out from the transcripts and ordered in a word table for each environment.

2) The content in each table was inductively sorted into descriptive categories. For instance, in relation to collaboration, such categories could be "difficult to cowrite" or "able to co-write".

3) Contextual explanations to the categories were analysed by asking why it was "difficult to co-write", for instance, or how some were "able to co-write". At this stage, the overall case was taken into account to explain the findings with respect to the environment's and individuals' disciplinary orientations, the physical location of the members, their academic positions and academic networks, as well as how the doctoral school was organised more generally.

4) The two tables were then compared with each other to find the common and diverging points, both in terms of descriptive categories and contextual explanations.

5) In the synthetic step of the analysis, the descriptive categories and contextual explanations were further analysed by searching for deeper cross-cutting explanations to the patterns of collaboration and independence. This was an interpretative phase where the participants' patterns were related to their overall experience of their multidisciplinary environment. We could then identify different epistemic living spaces in the environment that shaped the individuals' learning space and potential scope of action within it.

6) In the final step of the analysis, the participants were positioned in relation to one another depending on their relative positions in time and space.

During any interpretive process, one's own professional background can be expected to affect the interpretative horizons. Neither of the authors were involved in the studied environments, but both had extensive experience of working across disciplines in their own prior education, as well as in teaching, research and development of higher education. Thus, besides drawing on theoretical insights, our own experiences helped to detect critical aspects that have been less elaborated in the 
literature. To strengthen the analytical trustworthiness of our interpretations, we have used participant validation of the presented results.

\section{Ethics}

According to the Swedish regulations for conducting research on humans, there was no need to seek ethical clearance for this study, since it did not involve sensitive topics or vulnerable participants in the sense of the law (SFS 2003: 460). All participation was voluntary after informed consent, and the participants could withdraw from the study at any time. In order to protect the participants' identity, revealing information has been removed from the results such as specific faculty, discipline, gender, ethnicity, and age. Furthermore, before data were analysed, all participants were invited to confirm their own interview transcripts and remove quotations that they did not want to share with others. A draft of the manuscript as a whole was also read by the participants, to ensure that they felt their quotations were appropriately contextualised.

\section{Methodological Considerations}

Our research design aimed to create an empirically based conceptual framework that can be useful for analysing and understanding temporal and spatial conditions in multidisciplinary learning environments. However, not all members of the environments were interviewed, which limits the scope of our conceptual framework. Additionally, our choice to investigate only two environments means that participants might have been selective in what they shared in the interviews, considering that the final results would be read by their colleagues. Junior scholars are particularly vulnerable, as they are in a dependent relationship to the senior scholars, but also leaders and senior researchers may have avoided issues they perceived as problematic. It can therefore be anticipated that some divergent perspectives may be missing in our picture.

\section{Results}

Genuine cross-disciplinary research is not born over a night but requires many years of communication between members of an emerging community who are willing to learn from each other. Thus, findings from this study should be understood as temporally situated, where the patterns of collaboration and independence reflect how the environments and participants were developing at the time of data collection.

The overall results illustrate how the participants' career stages, disciplinary backgrounds, and current organisational affiliations were all factors that conditioned their scope of action and sense of belonging. More specifically, we could distinguish four ways of experiencing the multidisciplinary learning environment: $A$ world of opportunities, An alien world, An avoided world, and A joint world. These represent different epistemic living spaces, depending on how the available opportunities were 
perceived and used. Each epistemic living space also formed a learning space, supporting or hampering various forms of cross-disciplinary collaboration and scholarly independence, depending on the participants' relative positions in time and space.

\section{A World of Opportunities}

In both environments, most participants agreed that the plurality of disciplinary competencies provided a world of "opportunities", with a pool of resources whenever you needed someone's disciplinary expertise, for instance, or if you needed a non-expert who could read your manuscript. Yet in the end, it was up to each individual to navigate in the system and collaborate with others, as one doctoral student pointed out:

No matter what the environment here provides... It provides you possibilities, but you have to take them, and you have to make it happen yourself. (Bd4)

The existence of this world of opportunities appeared to be highly dependent on the leaders' continuous strategic and boundary-crossing networking in the otherwise disciplinarily ordered academia:

If you're outside this [academic] system, you're questioned all the time, and then there are two ways to create legitimacy for yourself. One is to have a lot of money, because then you can always buy your legitimacy, but the other is that you have good relations with those who have their legitimacy for free by being in the [disciplinary] system. And if they think that our practice is important and want to contribute in some way - that creates a lot of legitimacy. (BHE)

The multidisciplinary epistemic living space was thus shaped by political and economic powers along with the willingness of senior members and peers to contribute with their disciplinary expertise. In this way, the involved disciplines attained varying symbolic and practical values. Although the doctoral schools had been established to create opportunities for cross-disciplinary work, there was no consensus among senior researchers concerning what this implied in practice, and relatively little space was offered for discussions with the early stage researchers on the issues that arose. Disciplinary boundaries were either indistinct or invisible, and some doctoral students wondered about the cross-disciplinary traces of their work. This uncertainty was especially expressed by those who were supposed to graduate in a mono-disciplinary department, while being connected to a cross-disciplinary graduate school at the same time. It was also expressed by a post doc who originally came from a mono-disciplinary environment:

Now that I have started as a post doc, I look in all directions: Who can teach me? What shall I learn? How can I make this interdisciplinary? But, there things have come to a standstill. It doesn't become interdisciplinary or multidisciplinary or whatever it is.... I feel I would like to do this, partly for my own development, but also because I want to do real interdisciplinary research. But it's terribly difficult for me to learn something when I don't know what I need to learn. (Bp1) 
Hence, even though the world of opportunities offered an epistemic living space for learning in almost any direction, the opportunity to turn the possibilities into concrete work was restricted by the lack of explicit and guiding structures for how to do cross-disciplinary research. In environment B, where the students could choose to graduate in the environment's cross-disciplinary core discipline, the lack of such guiding structures also had consequences for the examination. As one supervisor said: "the senior researchers disagree about what an interdisciplinary thesis should look like" (Bs4).

Thus, the world of opportunities appeared to also be a world of tensions. In environment $\mathrm{A}$, continuous efforts had been made to bridge disciplinary differences at the seminars, but some supervisors had experienced difficulties to "stop holding one's own position" in the beginning (As2). In environment B, there were ongoing discussions about the intellectual boundaries. While some advocated clearer boundaries that would define the environment's scholarly body in relation to other disciplines, others thought that this would exclude people in a destructive way from the perspective of "interdisciplinarity". This negotiation about the epistemic living space could be found among both supervisors and doctoral students, although the latter mostly asked for firmer boundaries, since they sometimes felt lost in their direction of research. Lack of clarity inhibited independent development, as one doctoral student explained:

Of course, I had the chance to be more open and hinge upon a larger set of perspectives or theories or whatever, but at the same time it has been hard not to have a clear reference or a clear school in a way of belonging to... So, although it's also an advantage, and probably part of the goal with the research school, it has represented an obstacle in a way, to becoming independent. For instance, what kind of journals do I want to get my stuff published in and what kind of quality standards do I have to try to meet in the work I do... Not having a clear set of answers to even such blunt questions has been a problem. (Bd3)

Against this background, the multidisciplinary epistemic living space occasionally appeared to offer too many epistemic and social opportunities for early stage researchers to handle without clear, explicit and concrete guiding structures for doing cross-disciplinary research. As we shall see, this also had varying consequences for their learning spaces, where collaborative projects between peers were not usual praxis, so that scholarly independence was sometimes rather formed in other developmental networks.

\section{An Alien World}

The environments' epistemic living spaces had become a socially distanced sphere for some participants, who felt that their knowledge contributions were not received as a part of the bigger picture. Although they had initially engaged in opportunities for cross-disciplinary discussions, as they advanced in their projects, the experienced lack of acceptance and understanding regarding basic epistemic premises became an obstacle to conversations where they could get 
valuable comments from others in the environment. This could happen when the disciplines were too far away from each other, and when the participants lacked basic knowledge about theories and methods beyond their own faculty traditions:

I always have to fight with the fact that no one knows my theoretical basis. I mean, it's self-evident for me, and when it comes to methods I always have to, kind of, start all over again and explain how you do in the HSS faculties - which is rather well-known in my discipline, and then they become like...??? In the end, you don't become critical towards your own work because you never reach that point. I just come to the point where I have to explain my basis, and be criticised for this basis, and defend it. (Ap3)

Especially the post docs felt this way in both environments, and therefore rather used their multidisciplinary environment as a platform for external networking and collaboration. However, similar concerns were raised by the doctoral students and environmental leaders, who also wished there was a better balance between the faculties and disciplines at the seminars. Both environments struggled with the fact that some faculties had become over-represented in their scholarly discussions over the course of time, so that researchers from other traditions had difficulties with finding their place in the alien community:

I had to have a distance from belonging to the community. I had to choose, because I could not combine the two [my own perspective with the others']. It always felt like I have to compromise with someone else or that I cannot do what I want to because no one else knows what I am doing... Oh yes, I should add that there $i s$ one project here that I can relate to... we have a common understanding of the importance of the concept that I use. (Bp2)

However, post docs from the dominating disciplines also felt lonely sometimes and missed a genuine dialogue about their projects in the environment, since time constraints left little space to engage deeply in issues relating to the work of other researchers. Hence, in relation to developing independence, one post doc remarked:

I do not think it's the environment as such [that contributes to my independent development], but I believe it's more the project that forces me to it... You know, people are so busy in their own projects, so if their project is not interdisciplinary in itself - then they don't grab someone else to hear about their thoughts. And when you present at seminars... it's like: I'm working in project $Y$, so I'll look at your X-project with my Y-eyes. No matter that I come from another faculty, I'll still look at your project based on my knowledge from project $Y$... I mean, the focus of the discussion slips away to others' projects. (Ap1)

Thus, almost all post docs more or less explicitly expressed that they had been forced to become "over-independent" in their environment. Most of them asked for support elsewhere since they felt that "no one here is interested in my work", as several of them phrased it in both environments. One post doc further explained: 
I'm funded by an institution that doesn't ask much of me, except some reports at the end of the year. They basically want to cover numbers, so it's irrelevant what I do. And I choose my research topics, I go about my research, so yeah. I cannot be more independent... But if I think about it, then I'm over-independent... my social networks here are still very weak. (Bp3)

Since the experience of not really belonging to the multidisciplinary environment was typical for the post docs, it is worth noting that their temporal position had certain consequences for their learning space. In contrast to the doctoral students, who were temporally and spatially positioned in a research school with both supervisors and peers, the post docs lacked such organisational anchoring.

The head of the environment B gave some clues to why this situation had arisen:

I want to create an environment where doctoral students have a lot of collaboration with colleagues in the same situation. They learn from each other in a much more equal way than you do with a doctoral student-supervisor [relationship]... the doctoral student is the most dynamic level as I see it, as they're still open and curious and try to make the most of the opportunities... The post doc has a very narrow task though. That is, to qualify yourself in two years to get a tenure. And the post doc should not be busy with comprehensive thinking, but they should focus on themselves. (BHE)

The post docs thus searched for their developmental networks elsewhere and tended to develop their scholarly independence away from the environment's community - which they experienced as an alien world.

\section{An Avoided World}

Among the mono-disciplinary doctoral students, the cross-disciplinary world of opportunities sometimes became an avoided world. Like the post docs, these doctoral students preferred to engage in other epistemic and social learning spaces. However, unlike the post docs (who worked across disciplines), their epistemic living space was primarily a mono-disciplinary sphere related to the department of their main supervisor. The students' choice to prioritise recognition in their "homediscipline" could be related to the weak cross-disciplinary commitment of those senior scholars who restricted their participation in the environments to a minimum. The absence of seniors at the seminars, for instance, caused difficulties for doctoral students who tried to collaborate with each other:

Among our PhDs... as soon as we start doing something they say: 'Well these are out of my department's interests, so why should I participate in this?' Or: 'I have a different perception about this particular subject.' So, it has been really hard, actually, to work among PhDs... I think it's because of the departments. My perception is that they are really restricted to their boundaries, so they're not really encouraging PhDs at any level to be more involved in our research school. So therefore, I understand why someone from another discipline is not participating in our seminars, because the head of that department never has 
been participating, and why should he or she? So, I don't blame the $\mathrm{PhDs}$ at all. (Bd5)

In this situation, several doctoral students displayed an attitude of opting out - non-collective independence - which the leaders and some supervisors perceived as a significant problem. A decreased number of potential arenas for communicating one's research reduced the opportunities to explicitly position their research in relation to others, and thereby also implied a restricted scope for developing scholarly independence. As the head of environment B explained:

In one way, the doctoral students are very independent and drive their own projects and ideas quite hard. However, they need to be prepared to discuss their own position in this group... We put rather much weight on that the students shall be able to communicate their research as independent good researchers. And I think that our doctoral students are pretty terrific when it comes to presenting at conferences and discussing. (BHE)

Thus, to improve the cross-disciplinary conditions, one supervisor (Bs2) planned to collaborate with seniors from other faculties in a near future and become a role model for the students. One of the doctoral students thought that the interdisciplinary communication had been easier in the beginning before the students "had started to position themselves" (Bd3), and yet another pointed out that "in the end they need to defend a PhD in their own discipline" (Bd4). This also reveals a crucial difference between the post docs and the doctoral students' epistemic conditions. Whereas those students who chose not to engage in processes within the environment did so because of their mono-disciplinary spatial positions, the post docs rather suffered from their temporal positions. However, the head of environment A, who was also struggling with unbalanced participation from their faculties believed that the basic problem with disciplinary absent members was a financial issue:

A real problem in this - and then we are unfortunately talking about money - is that our environment builds on the principle of co-funding [from the faculties besides the external grants]. Then the STEM faculties invest the most, and the HSS faculty hardly invests any money at all. And, of course, the big faculties who have contributed with much co-funding want something back [in terms of doctoral students and post docs at their faculties]. And I have tried again at the HSS faculty: If we co-finance a doctoral student in one of our projects, would you like to finance the rest? Then they decline because they have the tradition to announce their doctoral student positions openly, that their students should do whatever they want in a specific discipline... (AHE)

\section{A Joint World}

The multidisciplinary epistemic living space was nevertheless experienced as a joint world in some respects. Even though all participants agreed that the specialised academic system was not really made for cross-disciplinary collaboration, and the environment leaders frequently had to negotiate with resistant faculties to run 
their multidisciplinary doctoral schools, the key to success was actually not a disciplinary issue in the first place. Instead, a complex process of compromising and learning seemed to be the most important condition for successful collaboration. One post doc who collaborated with others outside the multidisciplinary environment explained:

I'm involved in a study with another faculty, and then we have different languages... Are you allowed to say this and that concept, and what do you mean with these concepts? However, as far as you're prepared that you need to handle this, then you go into the collaboration with a positive attitude, and everyone involved has to compromise a little bit here and there. Well, not everyone - but at least you have to decide how you're going to do in this cooperation or what kind of reference frames you're going to lean on... And if I'm not used to work with this, then I have to read and learn about the alternative. (Ap2)

In environment $\mathrm{A}$, no such internal cross-disciplinary collaboration was reported among the doctoral students, but they did participate in the multidisciplinary seminars and courses on a regular basis. The seminars created a joint learning space, where varying disciplinary concepts, theories, and methods could be discussed. While such engagement was also typical in environment B, the early stage researchers had some collaborative projects going on as well. Goal-oriented interdisciplinary collaboration occurred in a smaller group of doctoral students who had decided to approach a common problem from their disciplinary diverse angles, and there was also an example of unidirectional interdisciplinary collaboration between a post doc and a doctoral student from different HSS faculties. In the latter case, they initially found it very difficult to co-write an article, but after a while they decided that the doctoral student's perspective would take the lead and finally managed to publish their article:

There was much written about our topic from a certain perspective... and we wanted to highlight that there was another side as well. However, we couldn't spin further on that side only, but we needed to combine several perspectives where the doctoral student's disciplinary angle became the dominating and mine was added. Then we succeeded, but before we found this way... you know, we have very different perceptions of these concepts... and we had to sit down seriously and have a lot of meetings about this. (Bp2)

Otherwise, internal cross-disciplinary peer collaboration was rare in environment $\mathrm{B}$, which also limited its potential learning space in this respect. The most important key to success seemed to be a genuine interest in cross-disciplinary communication per se, without too much emphasis on producing results in the first place. In turn, this implied a willingness to invest enough time to be able to find the connections, in spite of the individuals' varying backgrounds:

I believe that you need to be interested in the process itself, to invest time that can be wasted - that does not necessarily need to result in something productive... There is one such good example [in the environment], and the members of that group come from very different disciplines... All of them seem 
to be interested in, and find it exciting: Who am I? What do I want in this process? They're interested in the process itself and in that they're so different... I was in another group... sigh... all came from the same HSS faculty, but the interdisciplinary conditions were not that good at all. I feel that people are not interested, because they do not get something out of it... people are not interested in the discussion and the process itself. (Bp1)

Even though the joint world had social and developmental benefits, it came at an epistemic price. The more disciplinary integration the $\mathrm{PhD}$ thesis achieved, the more distance was created to clearly bounded disciplines:

This thesis would not pass in any other discipline, I guess. They would be like: 'What are you doing? It is not consistent or coherent!' But it is coherent, it's just in a different way. (Bd4)

Another doctoral student thought that it was "really helpful" to have a supervisor in the cross-disciplinary core discipline of the environment "who actually understands why you are doing this" (Bd5). Also in other respects it could be difficult to be accepted outside the interdisciplinary field itself, since generalists and openminded disciplinary experts were often lacking in other contexts, as one post doc had noticed:

You combine different approaches... and then you try to publish. And what will happen? You'll have reviewers from each of these sides criticising what you say and don't say. I've given up... I'm not willing to discuss with different people that are pulling this in different directions, it's just not worth it... And I'm not the only one. I've spoken to other people to whom this has also happened. (Bp3)

Accordingly, independent positioning worked very well within the environment from this perspective, while it could be troublesome elsewhere.

\section{Grasping the Whole Picture}

For an illustrative overview of our theoretical construction see Fig. 1, where the grey field represents the overall epistemic living space of the multidisciplinary learning environments. Through the leaders' networking, the world of opportunities offered varying possibilities for both internal and external collaboration, which took the form of either multidisciplinary or cross-disciplinary activities. However, the individual members' orientations differed depending on their epistemic and social spaces (spatial position) and career stage (temporal position). This meant that the spatial or temporal conditions had different implications for the early stage researchers' opportunities to collaborate and develop independence (see double arrow below the grey field). All in all, their orientations were impacted by varying experiences of the world of opportunities, which became an alien, avoided, or joint world dependent on the dominating conditions for the individual participants. The environments' optimal learning space is found at the top of the figure, where there is a balance between the spatial and temporal conditions for the individual's scope of action. 


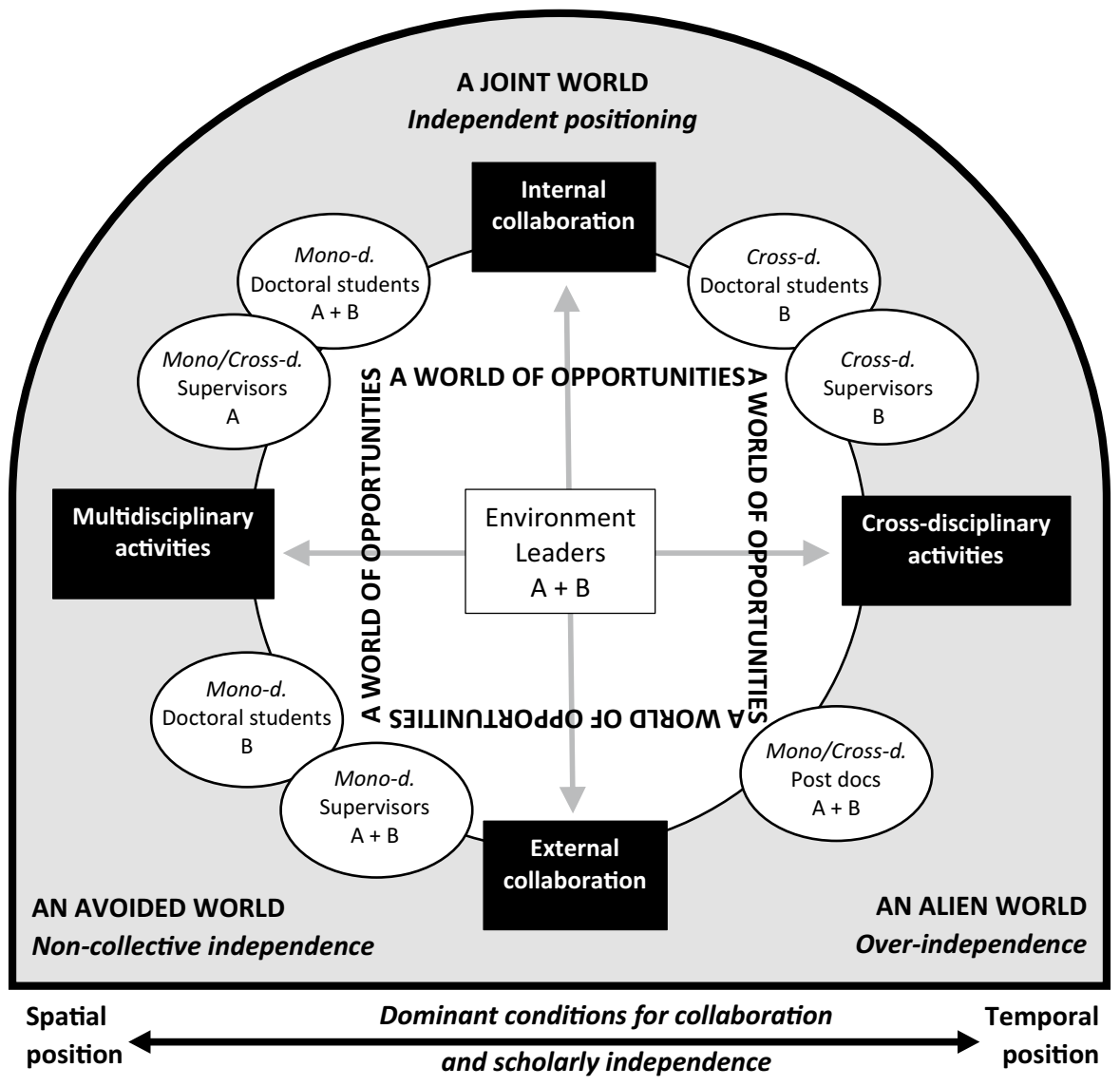

Fig. 1 Main orientations in the environments and their relative positions in time and space

The most critical point with these results is the absence of post docs in the joint world. First and foremost, this world was built around the doctoral students who used their internal developmental networks for independently positioning themselves through and within the community. The post docs were seldom involved in this collaborative capacity-building, but rather developed their independence away from the community in their own epistemic living spaces.

\section{Discussion and Suggestions for Developing Practice}

Seen from a bird's eye perspective, the leaders constituted the nexuses of the environments by connecting all the parts together, ranging from the different types of cross-disciplinary activities, to conditions for internal and external collaboration. In line with other studies (Frost et al. 2004; Martimianakis and Muzzin 2015), these integrative efforts implied a never-ending process of strategic communication and 
negotiation across the faculties and with other stakeholders. The leaders had been able to create an epistemic living space (Felt et al. 2013) that offered a world of opportunities, even though its potentials had not always been fully realised for two reasons. On the one hand, institutional and economic structures in academia affected the position of the disciplines, which had consequences for cross-disciplinary work. Environment A had become dominated by disciplines from the STEM faculties that contributed the most with funding, which in turn weakened the epistemic voices from the HSS disciplines. How funding can inhibit cross-disciplinary ambitions in this way has been noticed in other studies as well (e.g. see Albert et al. 2009; Jakobsen et al. 2004; Kessel and Rosenfield 2008). On the other hand, the individuals' spatial and temporal positions led to dynamics where the world of opportunities became either an alien, avoided, or joint world, which in turn formed varying learning spaces for the early stage researchers. Thus, the extent to which the environments corresponded to the needs and constraints of different groups ultimately also scoped their opportunities for collaboration and development of scholarly independence.

\section{The Temporally Conditioned Learning Space in the Alien World}

The world of opportunities turned out to be an alien world for the post docs, who experienced a socially distanced sphere when their projects did not match the epistemic practice of the other members. They did not feel they really fit in, and most post docs in both environments thought that the others were not interested in their research. Since the multidisciplinary environment did not offer a developmental network (Baker and Lattuca 2010) for these post docs, they had been forced to become "over-independent" and form their own cross-disciplinary epistemic living spaces, away from the community of the environment itself. Notwithstanding, although they found it difficult to see the possible connections, especially those from environment B expressed that they would like to be more involved with others in the environment. This finding suggests that devoting additional time to communication about how varying projects could be related to each other might create more inclusive learning spaces.

Scaffidi and Berman (2011) have noted that post docs in general need support from scientific supervisors and career mentors, and in our own study, one of the post docs with a mono-disciplinary background (Bp1) had asked for support in how to make cross-disciplinary research. From our results, it appeared that the post docs' temporal career positions had a counterproductive effect in this regard. Besides the fact that post docs are commonly assumed to be autonomous after their $\mathrm{PhD}$, one of the leaders (BHE) thought that they should focus on their own career rather than engaging in collaborative processes within the environments. Nonetheless, by not including the post docs in the idea of a collaborative community, the entire environment missed out on a valuable potential. Seen from a learning perspective, not only would more extensive collaboration strengthen internal developmental networks for doctoral students and post docs alike, but it would also widen their cross-disciplinary horizons when the senior researchers were beyond reach. In multidisciplinary environments with similar configurations 
and constraints to the cases described here, we believe that this aspect merits careful attention in the organisational development, although the importance of engaged senior researchers cannot be overestimated.

\section{The Spatially Conditioned Learning Space in the Avoided World}

Despite their significant role for the multidisciplinary learning space, the mono-disciplinary supervisors turned out to be the most distanced members. Even though they were all involved in the environments through their doctoral supervision, many of them seldom participated in the seminars or in other cross-disciplinary activities. These findings are hardly surprising, considering that the cognitive and social costs of migration are high for senior scholars (Braun 2012), and previous empirical studies on multidisciplinary learning environments reveal that they tend to prioritise their mono-disciplinary department (Calvert 2010; Gardner et al. 2014; Martimianakis and Muzzin 2015). In our interviews it additionally appeared that the mono-disciplinary supervisors' avoidant attitudes spilled over to their doctoral students. The world of opportunities then became an avoided world when these students chose to defend their department's interests rather than engaging in cross-disciplinary activities. In this way, they also exemplified the least constructive form of scholarly independence in relation to the environment: non-collective independence.

Most supervisors included in this study explicitly expressed their concern about the situation, and Bs 2 aspired to become a better role model for the students by starting to collaborate with senior researchers from other faculties. This could be a step in the right direction but would probably not be sufficient to address the underlying tensions or the unequal weight of largely mono-disciplinary structural and institutional drivers. The study of Delamont et al. (2000) shows that doctoral students with a mono-disciplinary background are more willing to adopt a cross-disciplinary identity when they are involved in sub-disciplinary areas where the individuals share the same interests, and it is therefore possible that organisational identification of such sub-areas could help. Structured support from the environment might also enable the doctoral students to identify and communicate what knowledge they have in common, and hence to find a common ground which would improve the collaborative conditions (cf. Öberg 2009).

Our results additionally indicate a need to strengthen supervisors' ability to supervise cross-disciplinary thesis projects. To our knowledge, there are no courses specifically designed for cross-disciplinary supervision in Sweden. Given that crossdisciplinary doctoral student projects are not uncommon, we suggest that initiating such supervision courses could be a task for educational developers. Again, this would only be a partial solution to the problem of absent supervisors in multidisciplinary learning environments, as the time-consuming duties at the supervisors' home departments remain (Gardner et al. 2014). We nonetheless believe that support in cross-disciplinary research supervision would offer motivation for supervisors to get more engaged in the multidisciplinary environments, and to develop an 
interest in the issues of cross-disciplinary research beyond the projects of their own students.

\section{The Temporally and Spatially Converged Learning Space in the Joint World}

While for the epistemic living space of the alien world, temporal constraints affected post docs ability to engage, and institutional or disciplinary drivers played a role for both doctoral students and supervisors in the avoided world, in the joint world, temporal and spatial conditions converged in enabling participants to benefit from learning opportunities. Given that the doctoral students were clearly integrated in the multidisciplinary environment by various organised learning activities, they had both the temporal and spatial prospects for engaging in the environments' epistemic living space. This also created the most optimal conditions for developing collaborative networks and scholarly independence.

In environment A, it appeared that the doctoral student's home discipline implied a spatially independent positioning in itself within the blended community, where peers and other scholars gave the (temporally positioned) doctoral student new input at the multidisciplinary seminars. Thus, they collaborated in the sense of having an informative dialogue across the disciplines (Lewis et al. 2012), which would not be possible in a mono-disciplinary learning environment. Since these doctoral students were all graduating in their home disciplines, these learning conditions became optimal for benefitting from the cross-disciplinary potentials of the environment.

In environment $\mathrm{B}$, there was a discursive emphasis on the doctoral students' need to independently position themselves in the field. Many of these students lacked a firm foundation in a single discipline. Besides interaction with peers and senior researchers from the environment's cross-disciplinary core discipline, input on theory and methodology from experts in other disciplines was required so that they could convincingly position themselves as independent scholars and create their own unique blended angle. This interaction had subsequently initiated some interdisciplinary collaborative projects of both goal-oriented and unidirectional kinds (cf. Jakobsen et al. 2004).

Even though the students involved in such collaborations had encountered epistemic and linguistic barriers known from the literature (Jakobsen et al. 2004), they had eventually found their way out from the initial difficulties by compromising and finding a common ground (Öberg 2009). But most important for our argument is that in both environments, the doctoral students' disciplinary 'homelessness' constituted the necessary conditions for learning. It did not matter if the student's epistemic position was mono-disciplinary (as in case A) or cross-disciplinary (as in case B), as long as this epistemic position was combined with an adequate developmental network in the multidisciplinary environment. 


\section{Concluding Remarks}

The picture of the studied environments is likely to change over time, while additional factors are likely to play a role in other contexts. Nevertheless, our study contributes with new empirical and theoretical insights in relation to existing research on multidisciplinary learning environments. Empirically, we have shown how the multidisciplinary epistemic living space can be understood in different ways, depending on early stage researchers' spatial and temporal positions, with consequences for their learning space. By this means, we have developed a new conceptual framework for understanding how and why early stage researchers develop varying kinds of collaboration and scholarly independence, and filled a knowledge gap in the literature.

Our results have also contributed to further theoretical understanding of the notion of 'epistemic living space' (Felt et al. 2013) by pointing to how it relates to early stage researchers need for 'developmental networks' (Baker and Lattuca 2010). Firstly, we have shown that one and the same multidisciplinary environment contains multiple epistemic living spaces. Not because of the involved disciplines per $s e$, but due to the individuals' temporal and spatial positions, where some develop away from the community and others develop through and toward the community. Secondly, our results also reveal that the optimal learning space for collaboration and development of independence appears when there is an integrated balance between the spatial and temporal conditions for the individuals' development. In this way, our study also contributes to further understanding of the theoretical notion of 'developmental networks'.

Acknowledgements Open access funding provided by Lund University.

Open Access This article is licensed under a Creative Commons Attribution 4.0 International License, which permits use, sharing, adaptation, distribution and reproduction in any medium or format, as long as you give appropriate credit to the original author(s) and the source, provide a link to the Creative Commons licence, and indicate if changes were made. The images or other third party material in this article are included in the article's Creative Commons licence, unless indicated otherwise in a credit line to the material. If material is not included in the article's Creative Commons licence and your intended use is not permitted by statutory regulation or exceeds the permitted use, you will need to obtain permission directly from the copyright holder. To view a copy of this licence, visit http://creativecommons.org/licen ses/by/4.0/.

\section{References}

Albert, Mathieu, Suzanne Laberge, and Brian D. Hodges. 2009. Boundary-work in the health research field: Biomedical and clinician scientists' perceptions of social science research. Minerva 47(2): 171-194.

Baker, Vicki L., and Lisa R. Lattuca. 2010. Developmental networks and learning: Toward an interdisciplinary perspective on identity development during doctoral study. Studies in Higher Education 35(7): 807-827.

Boden, Daniel, Maura Borrego, and Lynita K. Newswander. 2011. Student socialization in interdisciplinary doctoral education. Higher Education 62(6): 741-755. 
Boden, Daniel, Lisa D. McNair, and Maura Borrego. 2014. "Leave your discipline at the door": Matching expectations for interdisciplinary collaboration among faculty members. Higher Education in Review 11: 1-29.

Borrego, Maura, and Lynita K. Newswander. 2010. Definitions of interdisciplinary research: Toward graduate-level interdisciplinary learning outcomes. The Review of Higher Education 34(1): 61-84.

Bossio, Diana, Birgit Loch, Mark Schier, and Alexander Mazzolini. 2014. A roadmap for forming successful interdisciplinary education research collaborations: A reflective approach. Higher Education Research \& Development 33(2): 198-211.

Blöschl, G., G. Carr, C. Bucher, A.H. Farnleitner, H. Rechberger, W. Wagner, and M. Zessner. 2012. Promoting interdisciplinary education-The Vienna Doctoral Programme on Water Resource Systems. Hydrology and Earth System Sciences 16(2): 457-472.

Braun, Dietmar. 2012. Why do scientists migrate? A diffusion model. Minerva 50(4): 471-491.

Brew, Angela. 2008. Disciplinary and interdisciplinary affiliations of experienced researchers. Higher Education 56(4): 423-438.

Brodin, Eva M. 2016. Critical and creative thinking nexus: Learning experiences of doctoral students. Studies in Higher Education 41(6): 971-989.

Brodin, Eva M., and Helen Avery. 2014. Conditions for scholarly creativity in interdisciplinary doctoral education through an Aristotelian lens. In Creativity research: An inter-disciplinary and multi-disciplinary research handbook, ed. Eric Shiu, 273-294. London: Routledge.

Calvert, Jane. 2010. Systems biology, interdisciplinarity and disciplinary identity. In Collaboration in the new life sciences, eds. John N. Parker, Niki Vermeulen, and Bart Penders, 201-219. Farnham: Ashgate.

Delamont, Sara, Paul Atkinson, and Odette Parry. 2000. The doctoral experience: Success and failure in graduate school. London, New York: Falmer Press.

Felt, Ulrike (ed.). 2009. Knowing and living in academic research. Convergence and heterogeneity in research cultures in the European context. Prague: Institute of Sociology of the Academy of Sciences of the Czech Republic.

Felt, Ulrike, Judith Igelsböck, Andrea Schikowitz, and Thomas Völker. 2013. Growing into what? The (un-)disciplined socialisation of early stage researcher in transdisciplinary research. Higher Education 65(4): 511-524.

Frost, Susan H., Paul M. Jean, Daniel Teodorescu, and Amy Benson Brown. 2004. Research at the crossroads: How intellectual initiatives across disciplines evolve. The Review of Higher Education 27(4): 461-479.

Fuqua, Juliana. 2012. Toward a better understanding of the definition of transdisciplinary scientific collaboration. Californian Journal of Health Promotion 10(1): 6-13.

Gardner, Susan K., Jessica S. Jansujwicz, Karen Hutchins, Brittany Cline, and Vanessa Levesque. 2014. Socialization to interdisciplinarity: Faculty and student perspectives. Higher Education 67(3): 255-271.

Hackett, Edward J., and Diana R. Rhothen. 2009. The Snowbird Charrette: Integrative interdisciplinary collaboration in environmental research design. Minerva 47(4): 407-440.

Heidler, Richard. 2017. Epistemic cultures in conflict: The case of astronomy and high energy physics. Minerva 55(3): 249-277.

Holley, Karri A. 2015. Doctoral education and the development of an interdisciplinary identity. Innovations in Education and Teaching International 52(6): 642-652.

Jakobsen, Christine H., Tove Hels, and William J. McLaughlin. 2004. Barriers and facilitators to integration among scientists in transdisciplinary landscape analyses: A cross-country comparison. Forest Policy and Economics 6(1): 15-31.

Kessel, Frank, and Patricia L. Rosenfield. 2008. Toward transdisciplinary research: Historical and contemporary perspectives. American Journal of Preventive Medicine 35(2): 225-234.

Knorr Cetina, Karin. 1999. Epistemic cultures. How the sciences make knowledge. Cambridge, MA: Harvard University Press.

Lewis, Jamie, Andrew Bartlett, and Paul Atkinson. 2016. Hidden in the middle: Culture, value and reward in bioinformatics. Minerva 54(4): 471-490.

Lewis, Jenny M., Sandy Ross, and Thomas Holden. 2012. The how and why of academic collaboration: Disciplinary differences and policy implications. Higher Education 64(5): 693-708.

Martimianakis, Maria A., and Linda Muzzin. 2015. Discourses of interdisciplinarity and the shifting topography of academic work: Generational perspectives on facilitating and resisting neoliberalism. Studies in Higher Education 40(8): 1454-1470. 
Miller, J. Jay, Jacquelynn F. Duron, Emily Adlin Bosk, Megan Finno-Velasquez, and Kristin S. Abner. 2016. Peer-learning networks in social work doctoral education: An interdisciplinary model. Journal of Social Work Education 52(3): 360-371.

Newswander, Lynita K., and Maura Borrego. 2009. Engagement in two interdisciplinary graduate programs. Higher Education 58(4): 551-562.

Öberg, Gunilla. 2009. Facilitating interdisciplinary work: Using quality assessment to create common ground. Higher Education 57(4): 405-415.

Olson, Gary M., and Judith S. Olson. 2000. Distance matters. Human-Computer Interaction 15(2/3): $139-178$.

Rosenfield, Patricia L. 1992. The potential of transdisciplinary research for sustaining and extending linkages between the health and social sciences. Social Science \& Medicine 35(11): 1343-1357.

Ryan, Maureen M., Rachel S. Yeung, Michelle Bass, Meg Kapil, Suzanne Slater, and Kate Creedon. 2012. Developing research capacity among graduate students in an interdisciplinary environment. Higher Education Research \& Development 31(4): 557-569.

Scaffidi, Amelia K., and Judith E. Berman. 2011. A positive postdoctoral experience is related to quality supervision and career mentoring, collaborations, networking and a nurturing research environment. Higher Education 62(6): 685-698.

SFS 2003:460. Lag om etikprövning av forskning som avser människor. Ändrad t.o.m. SFS 2018:1999. [Act concerning the ethical review of research involving humans. With revisions made until SFS 2018:1999]. Stockholm: Ministry of Education.

Townsend, Tony, John Pisapia, and Jamila Razzaq. 2015. Fostering interdisciplinary research in universities: A case study of leadership, alignment and support. Studies in Higher Education 40(4): 658-675.

Turner, Kelly, Karina Benessaiah, Scott Warren, and David Iwaniec. 2015. Essential tensions in interdisciplinary scholarship: Navigating challenges in affect, epistemologies, and structure in environment-society research centers. Higher Education 70(4): 649-665.

UNESCO 2019. Broadening the application of the sustainability science approach. https://en.unesco.org/ sustainability-science/guidelines. Accessed 8 August 2019

Weingart, Peter, and Nico Stehr (eds.). 2000. Practising interdisciplinarity. Toronto: University of Toronto Press.

Wright, Claire, and Simon Ville. 2017. Visualising the interdisciplinary research field: The life cycle of economic history in Australia. Minerva 55(3): 321-340.

Yin, Robert K. 2014. Case study research. Design and methods, 5th ed. Thousand Oaks, CA: Sage Publications.

Publisher's Note Springer Nature remains neutral with regard to jurisdictional claims in published maps and institutional affiliations. 